\title{
THE TWO-PARAMETER FORMULA OF DEFAULT PROBABILITY TERM STRUCTURE
}

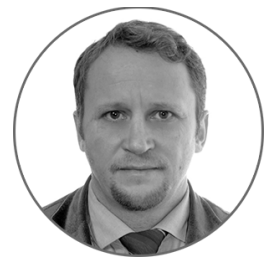

Article history:

Received 14 June 2018

Received in revised form

2 July 2018

Accepted 17 July 2018

Translated 13 November 2018

Available online 24 December 2018

JEL classification: $\mathrm{C} 58, \mathrm{G} 17, \mathrm{G} 28$

Keywords: credit risk, IFRS reserves, default probability, default term structure, IFRS 9

\author{
Mikhail V. POMAZANOV \\ National Research University Higher School of Economics, Moscow, Russian Federation \\ m.pomazanov@hse.ru \\ https://orcid.org/0000-0003-3069-1511
}

\begin{abstract}
Subject The article discusses the existing methods to model the term structure of default probability and their drawbacks affecting the practical use.

Objectives The research is aimed to make effective suggestions to creditors on setting the technique to evaluate the probability of the corporate borrower's default, considering a changeable term before the loan deal ends, without contradicting IFRS 9 - Financial Instruments.

Methods The research represents the economic and statistical analysis, optimizes aspects of special distributions based on statistical data of rating agencies.

Results I refer to consolidated empirical data of rating agencies on the corporate sector to substantiate the twoparameter formula of term structure of default probability, which does not contradict IFRS 9 with respect to corporate borrowers. In this case, internal bank data are insufficient to build the separate internal model $P D$ Lifetime or this process is too arduous.

Conclusions and Relevance I substantiate the default probability term structure formula, which is best in the pool of fitting distributions, being calibrated with empirically and statistically representative external data of rating agencies, covering a 44-year period. The formula is explicit, without implying complex calculations. The formula may prove useful in calculating the rate of reserves for loan assets, with their terms being coordinated with the principle lending mechanism (SPPI test) with respect to the second impairment phase under the classification given in IFRS 9.
\end{abstract}

The editor-in-charge of this article was Irina M. Vechkanova Authorized translation by Irina M. Vechkanova

\section{Introduction}

The probability of default (PD), as a key credit risk metric, is assessed for the nearest-year interval in line with the current macroeconomic forecast of the general credit risk profile for the year (point-in-time paradigm, PIT). The through-the-cycle paradigm (TTC) is alternative to the PIT paradigm. In the case of the TTC paradigm, the average annual PD is determined by the economic situation averaged through the cycle. Average

${ }^{\dagger}$ For the source article, please refer to: Помазанов М.В. Двухпараметрическая формула срочной структуры вероятности дефолта. Финансы и кредит. 2018. Т. 24. № 8.

С. 1920-1937. URL: https://doi.org/10.24891/fc.24.8.1920 estimated losses, which are backed with economic reserves, are based on the PD PIT. However, PD TTC should be used instead to evaluate the economic capital required to cover unforeseen losses, as per the approach proposed in the International Convergence of Capital Measurement and Capital Standards'. Neither formula requires the cumulative probability of default $P D(t)$ (for a random period $t$ ) to practically implement the advanced approach of Basel II Accord, since the average annual value is sufficient to estimate expected losses, while the maturity adjustment formula

\footnotetext{
${ }^{1}$ International Convergence of Capital Measurement and Capital Standards: A Revised Framework. Bank for International Settlements, 2004. URL: https://www.bis.org/publ/bcbs107.pdf
} 
may be used to measure the capital within the credit risk period ${ }^{2}$.

The adoption of IFRS 9 - Financial Instruments made it especially significant to correctly determine the cumulative probability (life cycle) $P D^{3}$. As per IFRS 9, expected losses should be assessed before the end of transactions term, which caused an increase in credit risk, i.e. those assets of the second tier (where the third tier is default as classified in IFRS 9). Therefore, there should be a proven technique to calculate the probability of default throughout the entire life cycle, at least, as $P D(t, P D 1)$, where $P D 1$ is the probability of default for the year $P D(1, P D 1)=P D 1$.

It is clear that the trivial lamp burnout formula ${ }^{4}$

$$
P D(t, P D 1)=1-(1-P D 1)^{t}
$$

is a too rough semblance, turning out to be conservative for $t$ of over 2 to 3 years. The formula is pretty applicable in case of $t<1$, indeed.

From fundamental perspectives, multiperiod assessments of $P D(t)$ are based on several approaches and their combination:

1) structural models of default through various dependencies of assets behavior;

2) models based on research into the proper population of clients, drawing upon survival models and maximum likelihood estimation method;

3) models based on the Markov chains (roll rate model) and migration of ratings;

4) direct fitting of dependence $P D(t)$ on the basis of observable statistics (including that of rating agencies).

The first approach is embedded into Basel II recommendations for capital adjustment since the economic capital measurement approach entirely draws upon the classic structural approach of Merton,

\footnotetext{
${ }^{2}$ Para. 272, International Convergence of Capital Measurement and Capital Standards: A Revised Framework. Bank for International Settlements, 2004. URL: https://www.bis.org/publ/bcbs107.pdf

${ }^{3}$ International Financial Reporting Standard 9 - Financial Instruments (edition of August 26, 2015). IFRS 9 was approved by Order of the Russian Ministry of Finance of April 2, 2013 № 36H and must be enforced starting from 2018.

URL: https://www.minfin.ru/ru/document/?id_4=117330

${ }^{4}$ Exponential dependency of the survival probability on time

$F(t, \lambda)=e^{(-\lambda t)}$, assessed on the basis of the independence of burnout probability at any point of time $t$ from $t$.
}

Black and Scholes [1]. The basic capital requirements evaluation formula was derived by O. Vasicek [2].

In the research referred to herein [3], authors focus on the classical perception of a default as an occasional impairment of assets down to the external debt level, with the theoretical behavior $P D(t)$ being described with the formula resulting from the Merton formula. However, the authors specify the parameters of the formula in line with the effective return on capital, which is measured with the company's rating. Consequently, the capital requirements evaluation approach for multiperiod transactions generates an adjustment which is very close to that stipulated in the Basel II Framework. Empirical calculations refer to four rating agencies' data on the cumulative probability of default in the periods of $\{1,2,3,4,5\}$ year with respect to several generalized rating grade $(A A A, A A, A, B B B, B B$, $B, C C C / C)$. It is noteworthy that $P D$ does not fit or fits badly to the AAA/A grades.

As for structural models of default probability [4, 5], a conditional time distribution before the default was used in the case of issuers with their default being unclearly observed or with noise. The model implies the default intensiveness prices, which depends on the current measurement of distance to default and other predictors, which may give additional information about the corporate position. The financial position of a company may be influenced by some diverse factors, including its corporate distinctions, size of the sector, macroeconomic cycle. All these variables are able to impact trends in payment flows and financial leverage. The structural model-based approach allows to accommodate other observable and unobservable predictors alongside with the distance-to-default metric in order to take into account credit risk causes, which are not covered with the distance-to-default metric.

The second approach to $P D$ life cycle measurement applies bank statistics, being best compliant with IFRS 9 (B5.5.52 Information of prior periods should be the starting point for further estimation of credit losses). It involves historical data on the life cycle of each particular asset in accordance with censoring, when an asset was opened before the beginning of the period, i.e. no default by the beginning of the period, with the moment of the planned cut-off of the asset taking place in the future as well as defaults of assets opened in the given period and defaults of those ones opened earlier. This method is based on the 
survival function which engenders the likelihood functionality and streamlines optimization issues. In addition to the time (age) parameter, the cumulative probability formula also comprises financial parameters of the asset, security parameters, macroparameters, homogeneous cyclical functions.

The mathematical structure of survivor models underlies the calculation processes described, say, in the research by N.M. Kiefer and C.E. Larson [6]. Such models work for mass (mostly retail) assets, being rather effective. The Cox proportionate hazards model is the most conventional [7] as presented in its contemporary interpretation by J. Bredeen [8]. The Cox model builds on the assumption that the risk function is decomposed into independent products. The first one depends on the exposition time, while parameters of the assets are what matters for the other. Subsequently, two independent predictors are set for the maximum likelihood function - for the term and parameters of the asset separately, thus simplifying the task.

The third approach is about the ultimate number of the borrower's states (rating grades). As part of the third approach, a transition rate matrix is built. During the continuous time Markov chain, the transition rate matrix for the period between dates 0 and $t$ is generated by taking the power of the generator matrix [9]. The generator matrix is squared by number of states $K \times K$ so that the transition rate matrix in the period looks like $(0, t) P(0 ; t)=\exp (G t)$. In the homogeneous time case, the product $G t$ constitutes the product of the matrix time a scalar number, while the exponential function is the ultimate amount:

$$
\exp (G t)=\frac{\sum_{(k=0)}^{\infty} t^{k}}{k !} \cdot G^{k}
$$

or $P(0, t)=\exp \left(\int_{0}^{t} G(t) d t\right)$ in non-homogenous case, where the generator function $G$ has the following properties $G_{(i, j)} \geq 0, i \neq j$ and $G_{(i, i)}=-\sum_{i \neq j} G_{(i, j)}$.

Capturing the frequency of state transitions in different periods of time through the maximum likelihood method, components of the generator matrix are assessed. The same is done for components of the transition rate matrix but in accordance with macroeconomic parameters $[10,11]$.

The blend of the third and fourth approaches implies a search for the non-homogeneous time generator matrix $G(t)$ using the fit matrix $\varphi(t)$, which is diagonal so that $G(t)=G \cdot \varphi(t)$,

$$
\varphi_{i, j}=\left\{\begin{array}{l}
0, \text { if } i \neq j \\
\varphi_{\alpha, \beta}(t), i=j
\end{array}, \quad \varphi_{\alpha, \beta}(t)=\frac{\left(1-e^{-\alpha t}\right) \cdot t^{\beta-1}}{1-e^{-\alpha}}\right.
$$

[12].

Parameters $\alpha, \beta$ are selected by minimizing approximation metrics to observations of the cumulative probability of default, which correspond with various rating grades assigned by Fitch and Standard \& Poor's. The two-state class of fit functions is subsequently used to set up the transition rate matrix for the arbitrary time $t$ using the formula (2). This method is applied to calculate the probability of default before the end of transactions with the Bulgarian corporate bonds [13] as part of making provisions and reserves under IFRS 9.

The above approaches (1 to 3 ) have considerable drawbacks constraining (but not preventing) their practical use. As for the first approach, it depends on the structural model, which is built on a family of arbitrary processes close to the Winner one. Therefore, deviations from real default statistics are usual and natural. Although being reasonably based on the real internal experience, the second approach requires extensive statistics so as to successfully apply evaluation algorithms. The $P D$ lifecycle evaluation algorithms are difficult to implement, entailing substantial costs and efforts. The third approach focuses on the ultimate set of rating grades, making the bank evaluate the transition rate matrix in a statistically flawless fashion as part of the internal rating method, and address the continuity issue of default probability assessed through the internal model and scaling it in line with the external one as part of the external rating method. Whereas the extrapolating function is difficult to exercise (for example, via Microsoft Excel), this complicates the practical use of the approach, especially if the accounting requirement to predict the model dependency is observed on the basis of macrofactors [14].

The default risk duration model has been proposed for the first time among arbitrary distribution-based 
approaches. Considering the term structure of default probability, the cumulative probability of corporate borrowers' default may presumably be described with the Weibull distribution ${ }^{5}$.

The research by D. Petrov and M. Pomazanov [15] presents a method to calculate the capital adjustment to the term using publicly available data released by rating agencies. Three-parameter function $P D(t)$ lays the basis for the fitting. Its parameters are calibrated with the dependence on PD (1 year). Analytical expressions are proposed, unveiling the term structure of default probability with the high precision fitting. To confirm/amend recommendations of Basel II Accord, we compare results we obtained in evaluating the capital adjustment and Basel term adjustment formula. The nature of the resultant dependencies mainly justifies the term adjustment recommendations. However, we discovered risk-exposed capital may be underestimated in the context of low default probability and maturity of two to three years.

I would like to point out some critical requirements of IFRS 9 concerning the $P D$ assessment within the protracted life of a loan.

1. $P D$ should be calculated on a sufficient sample. It means that the sample should be extensive so as to ensure a representative and meaningful view and verify characteristics of losses. Historical losses data should cover at least one full credit cycle.

2. If assessed for the credit life cycle, $P D$ should be conservatively based on respective extrapolating methods. When extrapolating methods are used to determine $P D$ lifelong metrics, expected credit loss $(E C L)$ should be estimated without any biases.

3. $P D$ estimates should accommodate forecasts, including macroeconomic factors in determining $P D$ life cycle so as to ensure losses are timely recognized.

4. Internal data should be employed to set $P D$ models, if possible, without excessive costs and efforts. The data should constitute a portfolio in the future.

5. If external data or suppliers' models are used, the external calibration example should be representative of the internal risk profile of the current population.

This research substantiates the best cumulative $P D$ calculation formula in the pool of fit distributions, which

\footnotetext{
${ }^{5}$ The distribution is given in the following point.
}

is calibrated with external representative data for the longest historical period of 40 and more years, for which such data are available. The formula depends on a cycle and may include information from macroeconomic forecasts. It can be preferably applied to corporate borrowers, the sample of which is not historically representative through internal data of a credit portfolio. The proposed extrapolation of default probability, which is applied to assess ECL-based reserves, does not contradict IFRS 9.

\section{Analysis of Two-Parameter Models of Default Probability Lifecycles through Rating Agencies' Statistics}

To find the distribution which would best describe the analyzable data, we compared the cumulative probability of issuers' default presented in the table and provided by rating agencies, and the presumed distribution function. The distribution function parameters were determined with the least square method.

The distribution efficiency metric is represented with $R^{2}$ :

$$
R^{2}=1-R S S / T S S
$$$$
R S S=\frac{1}{T} \cdot \sum_{t}\left(\frac{y-\hat{y}}{y}\right)^{2} \text {; }
$$

where $y$ denotes empirical data of a rating agency;

$\bar{y}$ denotes data on the cumulative probability of default for each rating grade, averaged for ten years;

$\hat{y}$ denotes the estimated probability of default predicted through an optimized model;

$T$ denotes the maximum duration of empirical sequence of terms.

Negative $R^{2}$ metric means that naive average approximation gives the best view of a range of values than the distribution. Negative $R^{2}$ will be excluded from the sample. The model with the highest $R^{2}$ is taken as the optimal specification for most ratings.

What kind of distributions should be taken into consideration for this purpose? The task may possibly be fulfilled with a decic polynomial but such a solution would not be optimal. Parametric models for default intensivity are suggested to include the Weibull distribution, log-logistic, log-normal and exponential 
distributions. The expanded list of expectedly useful distributions, which may work for the survival analysis, is given in the monograph by A.W. Marshall and I. Olkin [16]. The authors point out families of the following distributions and select only two-parameter ones ${ }^{6}$ :

1) exponential distributions:

- the Weibull distribution:

$$
F(x)=1-e^{-\lambda x^{\gamma}} ;
$$

- exponentially tilted distribution:

$$
F(x)=1-\frac{\gamma}{e^{-\lambda x}-(1-\gamma)} x \geq 0 ; \gamma, \lambda>0 ;
$$

2) logistic distributions:

- log-normal distribution:

$$
\begin{aligned}
& F(x)=N\left(N^{-1}(p)+\frac{\ln (x)}{\sigma}\right) x \geq 0 ; p \in(0,1), \\
& \sigma>0
\end{aligned}
$$

where $N(x), N^{-1}(x)$ denote direct and inverse normal distributions respectively;

- log-logistic distribution:

$$
F(x)=\frac{1}{1+(x \alpha)^{-\beta}} ;
$$

3) the Gomperz distribution:

- the Gompertz distribution:

$$
F(x)=1-\exp \left\{-\xi\left(e^{\lambda x}-1\right)\right\} x \geq 0 ; \xi, \lambda>0 ;
$$

- the negative Gompertz distribution:

$$
F(x)=1-\exp \left\{\xi\left(e^{\lambda x}-1\right)\right\} x \geq 0 ; \xi, \lambda>0 .
$$

To choose the best distribution for purposes of the research, I collected data on the average cumulative probability of corporate borrowers' default, which were provided by rating agencies Moody's, Standard \& Poor's, Fitch. The rating agencies have a different track record and credit rating methodology. Multiple gaps S\&P and Fitch left in investment rating charts is the first difficulty that arose during data processing. The collected statistics are not enough in the case of issuers with very high and very low ratings. That is why expert assessments are needed, rather than statistical inference. Due to this reason, it is logic to analyze a limited pool of ratings A1-Caa3. Different time horizon showing the data on the cumulative probability

\footnotetext{
${ }^{6}$ One-parameter distributions are rejected since they are evidently unable to be an effective extrapolation of $P D$ lifecycle.
}

of default is another distinctive feature. Some ratings of Moody's cover a 17-year span, while the other ones are given for a 20-year period. S\&P provides information for a 15-year period. Fitch unfolds data on the first five and ten years. That is why, cumulative terms of one to ten years were chosen for identical evaluation purposes. Empirical data were sourced from annual reports:

- Moody's ${ }^{7}$ - Corporate Default and Recovery Rates, 19202015, Exhibit 35 - Average Cumulative Issuer-Weighted Global Default Rates by Alphanumeric Rating, 19832015. The range of ratings $A 1 / C a a 3$ (15 grades);

- Standard\&Poor's ${ }^{8}$ - Default, Transition, and Recovery: 2015 Annual Global Corporate Default Study and Rating Transitions, Exhibit 26 Global Corporate Average Cumulative Default Rates by Rating Modifier (1981-2015). The range of ratings A+/B- (12 grades);

- Fitch ${ }^{9}$ - 2015 Transition \& Default Studies, Table Fitch Global Corporate Finance Average Cumulative Default Rates: 1990-2015. The range of ratings A/B(11 degrees).

The best distribution criterion is rather simple.

Distribution $A$ is better than distribution $B$, if estimates of distribution $A$ are higher than $R^{2}$ estimates of distribution $B$ in most of the ratings.

Empirical analysis of $R^{2}$ estimates with respect to optimal parameters of the same $R^{2}$ metrics gave the results presented in Table 1-3.

As a result of the empirical analysis, I conclude that the log-normal distribution is the most appropriate option to describe the structure of the default probability in the corporate finance segment among the proposed set of two-parameter families of distributions.

\section{Stationary Parameters of Log-Normal Distribution of Default Probability Term Structure as per Moody's (1983-2016)}

The log-normal structure of $P D$ time dependence is expressed as follows:

$$
P D(t, p, \sigma)=N\left(N^{-1}(p)+\frac{\ln (t)}{\sigma}\right)
$$

\footnotetext{
${ }^{7}$ Moody's. URL: https://www.moodys.com/pages/guidetodefaultrese arch.aspx

${ }^{8}$ Standard \& Poor's. URL: https://www.capitaliq.com

${ }^{9}$ Fitch Ratings. URL: https://www.fitchratings.com
} 
which has explicit economic interpretation of parameters:

- $P D(1, p, \sigma)=p$, i.e. parameter $\quad p$ is the probability of default within the year interval;

- parameter $\sigma$ determines the kurtosis of term curve $P D(t)$. The greater $\sigma$, the steeper the curve and the weaker the time dependence.

The log-normal distribution has the extreme value of the unconditional default intensity $\rho(t, p, \sigma)=\frac{d}{d t} P D(t, p, \sigma)$, which is seen within terms $T_{\max }=\exp \left(-\sigma \cdot N^{-1}(p)-\sigma^{2}\right)$.

The default intensity decreases within the term of transactions $t>T_{\max }$, which is not economically contradictory since the principal default intensity is more probable in the earlier period than the later one. The average time before default, which is weighted at

$$
\rho:=\int_{0}^{\infty} t \rho(t) d t=\exp \left(-\sigma \cdot N^{-1}(p)+\frac{\sigma^{2}}{2}\right) .
$$

It is obvious that an increase in $p$ reduces the term of maximum intensity and mean time before default.

To assess values and their properties, such as

- numerical value of $\sigma$;

- dependency of $\mathrm{p}$ on the rating grade (hereinafter denoted as $<P D 1>$ );

- comparison of the value with empirical PD1 (statistical default probability of a grade in a year);

- verification of the hypothesis on the dependency of $\sigma$ on $p$ within the averaged historical interval

let us refer to statistical data of Moody's. The data are presented in the Moody's report, Corporate Default and Recovery Rates, 1920-2016, Exhibit 35 - Average Cumulative Issuer-Weighted Global Default Rates by Alphanumeric Rating, 1983-2016. Ratings A1/Caa3 (15 grades), range of terms $-1,2, \ldots 20$ years.

The sum of squared deviations (3) reaches its lowest if the value of $\sigma$ equals 1.765. The optimization includes two steps. First, optimal values are found $<P D 1_{\text {Rating }}(\sigma)>$, meaning the minimum of relative squared deviation per each grade. Afterwards the value of $\sigma$, which minimizes the total sum of squared deviation for all the grades. Table 4 presents the results.
As Table 4 shows, model values of the average annual default probability $\angle P D>-1$ year are not significantly different from empirical values measured through historical data. However, the generally high level of interpolation quality (fitting) results from high $R^{2}$ (99+\%, except for Caa3). Fig. 1 depicts the extrapolation quality with respect to a sample of three dependencies of $P D$ term structure on grades.

The following step is to verify the hypothesis assuming that there is/is not monotonous dependence of values of $\sigma(p)$. It means each grade has the optimal

$\sigma_{\text {Rating }}$. The monotonous relation hypothesis is validated by evaluating Spearman's rank correlation ${ }^{10}$ between the rating and value of $\sigma_{\text {Rating }}$. Values of $\sigma_{\text {Rating }}$ are indicated in Fig. 2.

Spearman's rank correlation results in $R x y=-0.1$. The following formula serves to validate statistics relating to the dependence hypothesis:

$$
t=\frac{R x y \cdot \sqrt{n-2}}{\sqrt{1-R x y^{2}}}=0.375,
$$

It is subject to $t$-test (Student's $t$-test) with $n$-2 degree of freedom, where $n=15$ (the number of grades). The critical value of $t$, which makes the null hypothesis (zero dependence) with a 90 percent confidence is true, is tcrit. $(H 0)=0.13$. The critical value of $t$, which ensures the same confidence level of 90 percent, is tcrit. $(H 1)=1.78$. It means none of the hypothesis can be accepted at a 90 percent level. The zero dependence hypothesis can be approved at a 70-percent level but this confidence level is insufficient. Therefore, there are not reliable data to find the dependence of $\sigma(p)$. So, $\sigma(p)=$ const is quite a reasonable model, at least, in the case of the mean data of historical periods, i.e. in terms of TTC.

\section{PD Lifecycle Model in Line with the Current Economic Cycle}

Empirical analysis of PIT-dependency of the log-normal distribution parameter on an economic cycle is conducted on the basis of Moody's historical records reported in the same Corporate Default and Recovery Rates, 1920-2016, but in Exhibit 41 - Cumulative IssuerWeighted Default Rates by Annual Cohort, 1970-2016.

\footnotetext{
${ }^{10}$ For example, refer to Nasledov A.D. Matematicheskie metody psikhologicheskogo issledovaniya. Analiz i interpretatsiya dannykh [Mathematical methods for psychological research. Data analysis and interpretation]. St. Petersburg, Rech' Publ., 2004, 392 p.
} 
Exhibit 41 aggregates annual data on $P D$ term structure by consolidated rating grade $\{A a a, A a, A, B a a, B a, B$, Caa-C\}, including those averaged by SG class (Speculative-grade) from 1970 through 2016. The cyclical behavior of the parameter is studied through grades with a substantial statistical background of defaults $\{\mathrm{Baa}, \mathrm{Ba}, \mathrm{B}, \mathrm{Caa}-\mathrm{C}\}$. Average $P D 1$-year of $S G$ class is taken as the leading cycle indicator. The historical range of $P D$ term structure measurements is limited with 2013, which has four annual points of measure, with a maximum of 20 (the largest number of measurements is observed starting from 1997 and earlier), i.e. the number of annual measurements is 44 .

The optimal annual value of $\sigma$ (year) is computed through the same algorithm as is done in the previous point but for fewer rating grades (it does not depend on a grade. There four grades). After the $\sigma$ time series is measured (year), a statistical test is conducted to verify the hypothesis of significant Spearman's rank correlation between a series of 44 values PD1(year) and

$\sigma$ (year). Spearman's rank correlation generates the positive value of $R x y=0.6$, with the $t$-test of 4.84 appearing to be very high, thereby assuring the positive monotonous correlation hypothesis with the confidence level above 99 percent.

The cycle-based model of $\sigma$ (year) is set on the linear formula:

$$
\hat{\sigma}(\text { year })=\bar{\sigma}+\beta \cdot\left(\frac{P D 1(\text { year })-(P D 1)}{P D 1}\right),
$$

where $(\overline{P D} 1)$ is the mean value of $P D 1$ (year) (it equals 3.8 percent as per Moody's observation statistics for SG class), i.e. it refers to PD TTC in Moody's observations;

$\bar{\sigma}, \beta$ are parameters measured through the global minimum $R S S=\sum_{\text {year }} \frac{1}{T} \cdot \sum_{t}\left(\frac{y-\hat{y}}{y}\right)^{2}$ throughout the 1970-2013 observation period (44 points). Searching for the optimal values of $\bar{\sigma}, \beta$, I arrive at $\bar{\sigma}=1,552 ; \beta=0,412$.

Fig. 3 illustrates the comparison of empirical $\sigma$ (year) and model parameters of $\hat{o}$ (year). When average annual default probability reaches critical points, values of $\sigma$ increase, allowing for a greater slope of $P D$ term structure in the future.
Direct linear regression of cycle-based annual probabilities of default PD1 (year) by values of optimal

$\sigma$ (year) series through model (5) generates regression coefficients and their confidence intervals, indicated in Table 5.

Optimal parameters are close to regression one in accordance with the confidence interval, but they are preferable in terms of practical use since they result from direct minimization of errors (3) in accordance with the non-linear nature of the log-normal distribution in the case of $P D$ term structure.

\section{Conclusion}

Referring to consolidated empirical data rating agencies collected on the corporate sector, I substantiate the two-parameter formula of default probability term structure, which does not contradict requirements of IFRS 9 with respect to corporate borrowers. The sector of corporate borrowers lacks proper internal data, which would be sufficient to set the Lifetime $P D$ model. Otherwise such a model requires too much effort and time. To apply the formula, it is enough to calculate average annual probability of company's default PD1 using the internal model calibrated with sector mean $P D$ PIT and accommodating the macroeconomic forecast with respect to the sector. The formula is based on the log-normal family of distributions of dependency term structure $P D(T)$ given the exposition term (transaction term) $T>1$ year:

$$
\begin{aligned}
& P D(T)=N\left(N^{-1}(P D 1)+\frac{\ln (T)}{\sigma\left(P D_{P I T}, P D_{T T C}\right)}\right) \\
& \sigma\left(P D_{P I T}, P D_{T T C}\right)= \\
& =1.552+0.412\left(\frac{P D_{P I T}-P D_{T T C}}{P D_{T T C}}\right) .
\end{aligned}
$$

This article does not discuss the method to evaluate $P D_{P I T}, P D_{T T C}$ since it might be the subject of another research. If $T<1$ year, it is advisable to apply a well-known extrapolation formula of PD1 given the term is less than a year $P D(T)=1-(1-P D 1)^{T}$.

The probability of default $P D 1$ is computed by calibrating the rating or rating point measured through the internal model. The calibration technique and rating model setting process can be found in my earlier 
monograph ${ }^{11}$. The rating model based on financials of private sector corporations is proposed in the research by A. Karminskii [17].

The findings and results may have the following practical and theoretical scope of application:

- assessment of the rate of provisions for credit assets, when their terms correspond with the principal lending mechanism (SPPI test ${ }^{12}$ ) at the second impairment phase, as per the classification given in IFRS 9;

- internal assessment of economic capital requirements for a transaction in accordance with the term;

- assessment of the lowest (break-even) loan rate in line with risk and term of a transaction;

- optimization of the term of a transaction and other possible addenda.

\footnotetext{
${ }^{11}$ Pomazanov M.V. Upravlenie kreditnym riskom v banke: podkhod vnutrennikh reitingov (PVR) [Credit risk management in bank: Internal Ratings Approach]. Moscow, Yurait Publ., 2016, 265 p.

${ }^{12}$ For more details please refer to IFRS 9 (2013).
}

Please cite this article as: Pomazanov M.V. The Two-Parameter Formula of Default Probability Term Structure. Digest Finance, 2018, vol. 23, 


\section{Table 1}

Selection of the best-fit distribution, according to Moody's data

\begin{tabular}{llllllll}
\hline Rating & Max -sq & $\begin{array}{l}\text { Weibull } \\
\text { distribution }\end{array}$ & $\begin{array}{l}\text { Exponential } \\
\text { distribution with the } \\
\text { skewness parameter }\end{array}$ & $\begin{array}{l}\text { Log-normal } \\
\text { distribution }\end{array}$ & $\begin{array}{l}\text { Log-logistic } \\
\text { distribution }\end{array}$ & $\begin{array}{l}\text { Gompertz } \\
\text { distribution }\end{array}$ & $\begin{array}{l}\text { Negative } \\
\text { Gompertz } \\
\text { distribution }\end{array}$ \\
\hline A1 & Log-normal & 0.9959 & 0.9906 & 0.999 & 0.996 & 0.9906 & 0.9827 \\
\hline A2 & Log-logistics & 1 & 0.9957 & 0.9994 & 1 & 0.9957 & 0.9642 \\
\hline A3 & Log-normal & 0.9997 & 0.9947 & 0.9998 & 0.9997 & 0.9946 & 0.9717 \\
\hline Baa1 & Log-normal & 0.9959 & 0.9937 & 0.9991 & 0.9961 & 0.9936 & 0.9919 \\
\hline Baa2 & Log-logistic & 0.9997 & 0.9971 & 0.9995 & 0.9998 & 0.9971 & 0.987 \\
\hline Baa3 & Log-logistic & 1 & 0.9979 & 0.9986 & 1 & 0.9978 & 0.9861 \\
\hline Ba1 & Log-normal & 0.9925 & 0.9882 & 0.9984 & 0.9935 & 0.9881 & 0.9851 \\
\hline Ba2 & Log-normal & 0.9969 & 0.9948 & 0.9999 & 0.9975 & 0.9948 & 0.9922 \\
\hline Ba3 & Lo-normal & 0.9952 & 0.9916 & 0.9999 & 0.9971 & 0.9913 & 0.9872 \\
\hline B1 & Log-normal & 0.9969 & 0.994 & 0.9999 & 0.9988 & 0.9937 & 0.9897 \\
\hline B2 & Log-normal & 0.9913 & 0.9919 & 0.9992 & 0.9952 & 0.9957 & 0.992 \\
\hline B3 & Log-normal & 0.9949 & 0.996 & 0.9998 & 0.9984 & 0.9986 & 0.9962 \\
\hline Caa1 & Log-normal & 0.9848 & 0.9946 & 0.9964 & 0.991 & 0.9959 & 0.9914 \\
\hline Caa2 & $\begin{array}{l}\text { Exponential } \\
\text { distribution with the }\end{array}$ & 0.9981 & 1 & 0.9994 & 1 & 0.9823 & 0.9999 \\
& Skewness parameter & & & & & & 0.9934 \\
\hline Caa3 & Negative Gompertz & 0.9844 & 0.9578 & 0.9948 & 0.8006 & 0.9992 \\
\hline
\end{tabular}

Source:Authoring

Please cite this article as: Pomazanov M.V. The Two-Parameter Formula of Default Probability Term Structure. Digest Finance, 2018, vol. 23, iss. 4, pp. 419-432. 
Table 2

Selection of the best-fit distribution, according to S\&P data

\begin{tabular}{|c|c|c|c|c|c|c|c|}
\hline Rating & Max $R$-sq & $\begin{array}{l}\text { Weibull } \\
\text { distribution }\end{array}$ & $\begin{array}{l}\text { Exponential } \\
\text { distribution with the } \\
\text { skewness parameter }\end{array}$ & $\begin{array}{l}\text { Log-normal } \\
\text { distribution }\end{array}$ & $\begin{array}{l}\text { Log-logistic } \\
\text { distribution }\end{array}$ & $\begin{array}{l}\text { Gompertz } \\
\text { distribution }\end{array}$ & $\begin{array}{l}\text { Negative } \\
\text { Gompertz } \\
\text { distribution }\end{array}$ \\
\hline $\mathrm{A}^{+}$ & Log-normal & 0.9991 & 0.996 & 0.9992 & 0.9991 & 0.996 & 0.9828 \\
\hline $\mathrm{A}$ & Weibull distribution & 0.9994 & 0.999 & 0.9971 & 0.9994 & 0.999 & 0.9811 \\
\hline A- & Log-logistic & 0.9998 & 0.9978 & 0.9988 & 0.9998 & 0.9978 & 0.9872 \\
\hline $\mathrm{BBB}+$ & Log-normal & 0.9983 & 0.9958 & 0.9999 & 0.9984 & 0.9957 & 0.991 \\
\hline BBB & Log-logistic & 0.9997 & 0.998 & 0.9994 & 0.9998 & 0.998 & 0.9925 \\
\hline BBB- & Log-normal & 0.9924 & 0.9902 & 0.9979 & 0.993 & 0.9906 & 0.99 \\
\hline $\mathrm{BB}+$ & Log-normal & 0.9925 & 0.9904 & 0.9982 & 0.9933 & 0.9909 & 0.9904 \\
\hline $\mathrm{BB}$ & Log-normal & 0.9866 & 0.9869 & 0.9955 & 0.9883 & 0.9894 & 0.9854 \\
\hline BB- & Log-normal & 0.9895 & 0.989 & 0.9976 & 0.9917 & 0.992 & 0.989 \\
\hline $\mathrm{B}+$ & Exponential & 0.979 & 0.9947 & 0.9916 & 0.9831 & 0.9951 & 0.9879 \\
\hline B & $\begin{array}{l}\text { Negative Gompertz } \\
\text { distribution }\end{array}$ & 0.9662 & 0.9676 & 0.9812 & 0.9723 & 0.943 & 0.9937 \\
\hline B- & $\begin{array}{l}\text { Negative Gompertz } \\
\text { distribution }\end{array}$ & 0.968 & 0.9301 & 0.9825 & 0.9753 & 0.8715 & 0.998 \\
\hline
\end{tabular}

Source:Authoring

Table 3

Selection of the best-fit distribution, according to Fitch data

\begin{tabular}{|c|c|c|c|c|c|c|c|}
\hline Rating & Max $R$-sq & $\begin{array}{l}\text { Weibull } \\
\text { distribution }\end{array}$ & $\begin{array}{l}\text { Exponential } \\
\text { distribution with the } \\
\text { skewness parameter }\end{array}$ & $\begin{array}{l}\text { Log-normal } \\
\text { distribution }\end{array}$ & $\begin{array}{l}\text { Log-logistic } \\
\text { distribution }\end{array}$ & $\begin{array}{l}\text { Gompertz } \\
\text { distribution }\end{array}$ & $\begin{array}{l}\text { Negative } \\
\text { Gompertz } \\
\text { distribution }\end{array}$ \\
\hline A & Log-normal & 0.993 & 0.9823 & 0.9981 & 0.9932 & 0.9823 & 0.9543 \\
\hline A- & Gompertz distribution & 0.9701 & 0.9902 & 0.9523 & 0.9697 & 0.9903 & 0.953 \\
\hline $\mathrm{BBB}+$ & Log-normal & 0.9926 & 0.9855 & 0.9954 & 0.9928 & 0.9855 & 0.9663 \\
\hline BBB & Log-normal & 0.9831 & 0.9712 & 0.9931 & 0.9837 & 0.9712 & 0.9527 \\
\hline BBB- & Log-normal & 0.9989 & 0.9939 & 0.9994 & 0.9991 & 0.9938 & 0.9742 \\
\hline $\mathrm{BB}+$ & Gompertz distribution & 0.9527 & 0.9864 & 0.9731 & 0.9557 & 0.988 & 0.9665 \\
\hline $\mathrm{BB}$ & Log-normal & 0.9786 & 0.9762 & 0.9928 & 0.981 & 0.9793 & 0.9761 \\
\hline BB- & $\begin{array}{l}\text { Negative Gompertz } \\
\text { distribution }\end{array}$ & 0.9864 & 0.9583 & 0.9953 & 0.9878 & 0.9489 & 0.9995 \\
\hline$B-$ & $\begin{array}{l}\text { Exponential } \\
\text { distribution with the } \\
\text { skewness parameter }\end{array}$ & 0.86 & 0.9785 & 0.8909 & 0.8651 & 0.9777 & 0.9204 \\
\hline B & $\begin{array}{l}\text { Exponential distribution } \\
\text { with the skewness } \\
\text { parameter }\end{array}$ & 0.9259 & 0.9812 & 0.9528 & 0.9323 & 0.9747 & 0.9622 \\
\hline$B-$ & $\begin{array}{l}\text { Negative Gompertz } \\
\text { distribution }\end{array}$ & 0.8429 & 0.3564 & 0.8639 & 0.8465 & 0.297 & 0.9816 \\
\hline
\end{tabular}

Source:Authoring

Please cite this article as: Pomazanov M.V. The Two-Parameter Formula of Default Probability Term Structure. Digest Finance, 2018, vol. 23, iss. 4, pp. 419-432.

https://doi.org/10.24891/df.23.4.419 


\section{Table 4}

Values of optimal parameters of lognormal distribution, fitting the historical dependence of default probability on the term, Moody's data

\begin{tabular}{llllll}
\hline Rating & $P D-1$ year, $\%$ & $\langle P D>-1$ year, $\%$ & $R$-square, & $\begin{array}{l}\text { Average period before } \\
\text { default, years }\end{array}$ & $\begin{array}{l}\text { Term before PD intensity } \\
\text { maximum, years }\end{array}$ \\
\hline A1 & 0.07 & 0.04 & 99.92 & 1,780 & 16.6 \\
\hline A2 & 0.05 & 0.05 & 99.99 & 1,567 & 14.6 \\
\hline A3 & 0.06 & 0.05 & 100 & 1,552 & 14.5 \\
\hline Baa1 & 0.14 & 0.07 & 99.88 & 1,355 & 12.7 \\
\hline Baa2 & 0.18 & 0.11 & 99.97 & 1,040 & 9.7 \\
\hline Baa3 & 0.26 & 0.19 & 99.97 & 791 & 7.4 \\
\hline Ba1 & 0.47 & 0.53 & 99.99 & 433 & 3.4 \\
\hline Ba2 & 0.77 & 0.69 & 99.98 & 367 & 1.7 \\
\hline Ba3 & 1.47 & 2.02 & 99.87 & 177 & 1.2 \\
\hline B1 & 2.16 & 2.96 & 99.82 & 133 & 1 \\
\hline B2 & 3.21 & 3.97 & 99.89 & 105 & 0.7 \\
\hline B3 & 5.36 & 5.87 & 99.67 & 75 & 0.7 \\
\hline Caa1 & 5.16 & 6.13 & 99.78 & 72 & 0.4 \\
\hline Caa2 & 10.84 & 11 & 99.71 & 41 & 0.3 \\
\hline Caa3 & 20.45 & 15.72 & 89.65 & 28 & \\
\hline
\end{tabular}

Source:Authoring

\section{Table 5}

Model (5) coefficients estimation based on linear regression

\begin{tabular}{cllllll}
\hline Denotation & Coefficients & Standard errors & Lower 95\% & Upper 95\% & $\boldsymbol{t}$-test & $\boldsymbol{P}$-distribution \\
\hline $\boldsymbol{\sigma}$ & 1.672 & 0.06 & 1.55 & 1.79 & 29.5 & $1.08 \mathrm{E}-29$ \\
\hline $\boldsymbol{\beta}$ & 0.542 & 0.08 & 0.39 & 0.7 & 7.1 & $1.22 \mathrm{E}-08$ \\
\hline
\end{tabular}

Note. Regression statistics: Multiple $R-73,6 \%$; $R$-squared - 54.2\%; Normalized $R$-squared - 53.1\%; Standard error - 0.38; Observations - 44. Source:Authoring 


\section{Figure 1}

Extrapolated (solid curves) and observed values of default probability for different terms and the three categories of the Moody's rating at constant optimum value $\sigma$

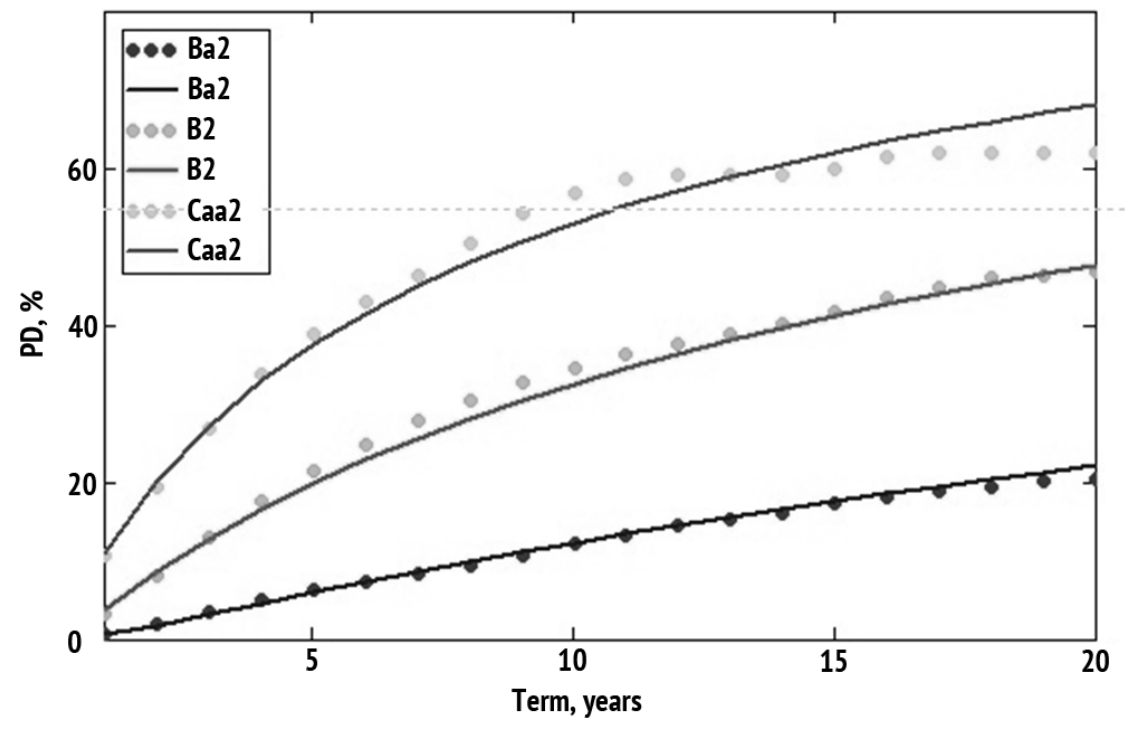

Source:Authoring

Figure 2

Values of $\sigma \quad$ (Rating) for the Moody's rating scale grades

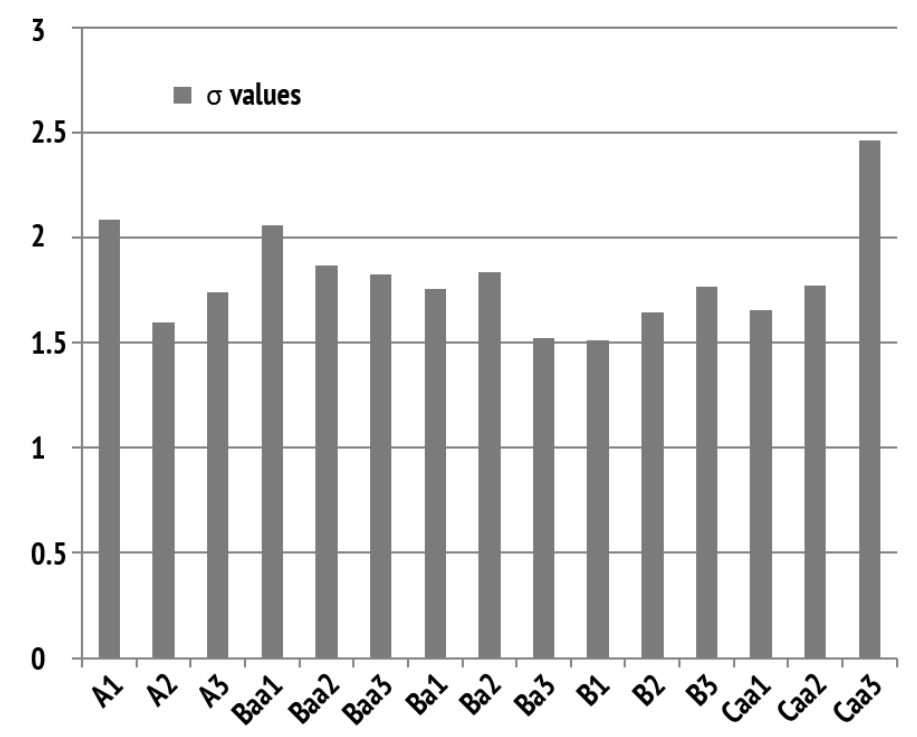

Source:Authoring

Please cite this article as: Pomazanov M.V. The Two-Parameter Formula of Default Probability Term Structure. Digest Finance, 2018, vol. 23, 


\section{Figure 3}

Time series of empirical and model values of log-normal distribution parameters $\sigma$ (Moody's data, 1970-2013), and the year-term default probabilities

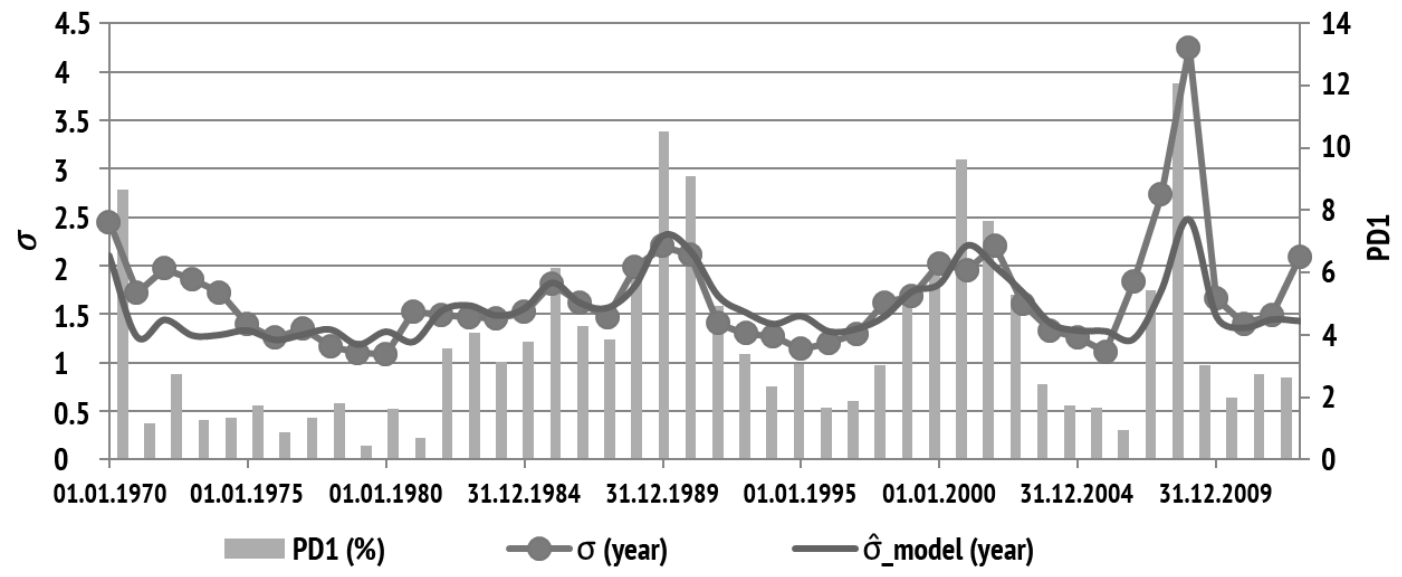

Source:Authoring

\section{Acknowledgments}

I express my gratitude to N.A. MORENKO, Graduate of the National Research University Higher School of Economics, for the data extracted from her thesis under the Master's Degree Program.

\section{References}

1. Merton R.C. On the Pricing of Corporate Debt: The Risk Structure of Interest Rates. The Journal of Finance, 1974, vol. 29, iss. 2, pp. 449-470.

URL: https://dspace.mit.edu/bitstream/handle/1721.1/1874/SWP-0684-14514372.pdf

2. Vasicek O. Loan Portfolio Value. Risk, 2002, vol. 15, no. 12, pp. 160-162.

3. Gürtler M., Heithecker D. Multi-Period Defaults and Maturity Effects on Economic Capital in a Ratings-based Default-mode Model. Working Papers Technische Universität Braunschweig, Institute of Finance, 2005, no. FW19V2. URL: https://www.econstor.eu/bitstream/10419/55248/1/684837757.pdf

4. Fisher E., Heinkel R., Zechner J. Dynamic Capital Structure Choice: Theory and Tests. The Journal of Finance, 1989, vol. 44, no. 1, pp. 19-40. URL: https://doi.org/10.2307/2328273

5. Duffie D., Lando D. Term Structure of Credit Spreads with Incomplete Accounting Information. Econometrica, 2001, vol. 69, iss. 3, pp. 633-664. URL: https://doi.org/10.1111/1468-0262.00208

6. Kiefer N.M., Larson C.E. Counting Processes for Retail Default Modeling. Journal of Credit Risk, 2015, vol. 11, iss. 3, pp. 45-72. URL: http://pure.au.dk/ws/files/86346097/rp15_17.pdf

7. Cox D.R. Regression Models and Life-Tables. Journal of the Royal Statistical Society. Series B (Methodological), 1972, vol. 34, no. 2, pp. 187-220. URL: http://www.stat.cmu.edu/ ryantibs/journalclub/cox_1972.pdf

8. Breeden J. Reinventing Retail Lending Analytics - Second Impression - Forecasting, Stress Testing, Capital and Scoring for a World of Crises. London, Risk Books, 2010, 433 p.

9. Israel R.B., Rosenthal J.S., Wei J.Z. Finding Generators for Markov Chains via Empirical Transition Matrices, with Applications to Credit Ratings. Mathematical Finance, 2001, vol. 11, iss. 2, pp. 245-265.

URL: https://doi.org/10.1111/1467-9965.00114

10. Brunel V., Roger B. Le Risque de Credit: Des Modeles au Pilotage des Banques. Economica, 2014.

Please cite this article as: Pomazanov M.V. The Two-Parameter Formula of Default Probability Term Structure. Digest Finance, 2018, vol. 23, iss. 4, pp. 419-432. https://doi.org/10.24891/df.23.4.419 
11. Brunel V. Loan Classication under IFRS 9. Risk, 2016, May, pp. 77-80.

12. Bluhm C., Overbeck L. Calibration of PD Term Structures: To Be Markov or Not To Be. Risk, 2007, vol. 20, no. 11, pp. 98-103. URL: http://www.christian-bluhm.net/Personal/Papers_files/nhctmc.pdf

13. Kristof T., Virag M. Lifetime Probability of Default Modeling for Hungarian Corporate Debt Instruments. URL: http://www.academia.edu/33180853/Lifetime_probability_of_default_modeling_for_Hungarian_corporate_ debt_instruments

14. VaněkT., Hampel D. The Probability of Default under IFRS 9: Multi-period Estimation and Macroeconomic Forecast. Acta Universitatis Agriculturae et Silviculturae Mendelianae Brunesis, 2017, vol. 65, iss. 2, pp. 759-776. URL: https://doi.org/10.11118/actaun201765020759

15. Petrov D., Pomazanov M. Validation Method of Maturity Adjustment Formula for Basel II Capital Requirement. The Journal of Risk Model Validation, 2009, vol. 3, iss. 3, pp. 81-97.

16. Marshall A.W., Olkin I. Life Distributions. New York, Springer, 2007, 783 p.

17. Karminskii A. [Corporate rating models for emerging markets]. Korporativnye finansy = Journal of Corporate Finance Research, 2011, vol. 5, iss. 3, pp. 19-29. (In Russ.) URL: https://cfjournal.hse.ru/article/view/1580/2298

\section{Conflict-of-interest notification}

I, the author of this article, bindingly and explicitly declare of the partial and total lack of actual or potential conflict of interest with any other third party whatsoever, which may arise as a result of the publication of this article. This statement relates to the study, data collection and interpretation, writing and preparation of the article, and the decision to submit the manuscript for publication. 